\title{
Characterization of Postdischarge-Nitrided 4140 Steel by XRD, SEM and HRTEM
}

\author{
A. Medina-Flores ${ }^{1}$, L. Béjar-Gómez ${ }^{1}$, H. Carreón ${ }^{1}$, A. Ruíz ${ }^{1}$, I. Alfonso² ${ }^{2}$ G. Herrera-Pérez ${ }^{3}$. \\ ${ }^{1 .}$ UMSNH. Ciudad Universitaria, Morelia, Michoacán. 58000. México. \\ 2. Universidad Autónoma del Carmen, Campus III. Avenida Central S/N, Esq. Fracc. Mundo Maya. C.P. \\ 24115, Ciudad del Carmen, Campeche, México. \\ 3. Departamento de Ingeniería en Materiales, Instituto Tecnológico Superior de Irapuato (ITESI) \\ Carretera Irapuato-Silao Km. 12.5, El Copal, Irapuato, Guanajuato. C.P. 36821, México
}

The positive effects of surface treatments like nitriding on fatigue and wear resistance of structural steels have been known for several decades [1-3]. Tools and components used in the severe environment must have excellent fatigue, corrosion and wear resistance. The surfaces of these components are required to attain high hardness values to resist wear, and inner cores still need to have high toughness strength [4,5]. Compared with conventional and plasma nitriding process, the post-discharge nitriding offers additional advantages, such us reduced treatment time, reduced distortion, demonstrates improved white layer control and it is environmentally friendly. Post-discharge nitriding is a microwave-activated thermochemical diffusion process where the reactive atmospheres are mainly composed of neutral excited species. The presence of neutral excited species results in higher nitride growth kinetics faster [6] which results in faster nitride growth kinetics normally associated to a rapid nitrogen surface saturation by diffusion without ion surface interaction, normally associated to plasma-assisted process. A serie of nitriding experiments were carried out in a 4140 steel in a post-discharge flow of plasma generated in the microwave reactor. The specimen was introduced into a tubular resistance furnace in an Ar- $\mathrm{H}_{2}$ post-discharge flow and heated to $810 \mathrm{~K}$ at $850 \mathrm{~Pa}$. Once the nitriding temperature was reached, the gas mixture was switched to $40 \mathrm{sccm}$ of $\mathrm{N}_{2}, 4 \mathrm{sccm}$ of $\mathrm{Ar}$ and $100 \mathrm{sccm}$ of $\mathrm{H}_{2}$ at a total pressure of $850 \mathrm{~Pa}$, the samples were treated during 5, 15 and 25 of nitriding time. The samples were then slowly cooled slowly in the reactor after nitriding under an Ar atmosphere. The nitriding samples were analyzed by X-ray diffraction (XRD) $\left(\lambda_{\mathrm{CuK} \alpha}=0.154 \mathrm{~nm}\right.$ ), scanning electron microscopy (SEM) and high resolution transmission electron microscopy (HRTEM). Figure 1 shows a X-Ray diffraction spectra treated for $5 \mathrm{~min}$ where it is possible to observe the formation of $\varepsilon-\mathrm{Fe}_{2-3} \mathrm{~N}$ and $\gamma^{\prime}-\mathrm{Fe}_{4} \mathrm{~N}$ nitrides on the top of the surface which occurs at short treatment time. Figure 2 shows a SEM image of a compact and homogeneous layer formed with about $13 \mu \mathrm{m}$ of thickness treated by $15 \mathrm{~min}$ of nitriding time. A HRTEM image is observed in figure 3 which shows a small precipitate of $\gamma^{\prime}-\mathrm{Fe}_{4} \mathrm{~N}$ formed during 25 min of nitriding with $8 \mathrm{~nm}$ of length with a interatomic distance of $0.189 \mathrm{~nm}$ which correspond at (200) plane, figures (a), (b) and (c) respectively. The structural results showed that as the nitriding time is increased, the compound layers formed on top surface changed from a dual phase $\left(\varepsilon-\mathrm{Fe}_{2-3} \mathrm{~N}\right.$ and $\gamma^{\prime}-$ $\mathrm{Fe}_{4} \mathrm{~N}$ ) to a monophase $\gamma^{\prime}-\mathrm{Fe}_{4} \mathrm{~N}$.

\section{References:}

[1] B. Edenhofer. Heat Treat. Met Volume 1 (1974), p. 23-31.

[2] T. J. Spalvins. Vac. Sci. Tech. A Volume 3 (1983), p. 23-29.

[3] T. Bell, et al. Surf. Eng. Volume 2 (1990), p. 133-138.

[4] C.M. Suh et al. I. J. of Mod. Phys B. Volume 17 (2003), p. 1663-1639

[5] C.M. Suh et al. Mat. Sci and Eng. A Volume 392 (2005), p. 31-37

[6] J. Oseguera, et al. Surf. Coat. Tech. Volume 95 (1997),p. 587592 


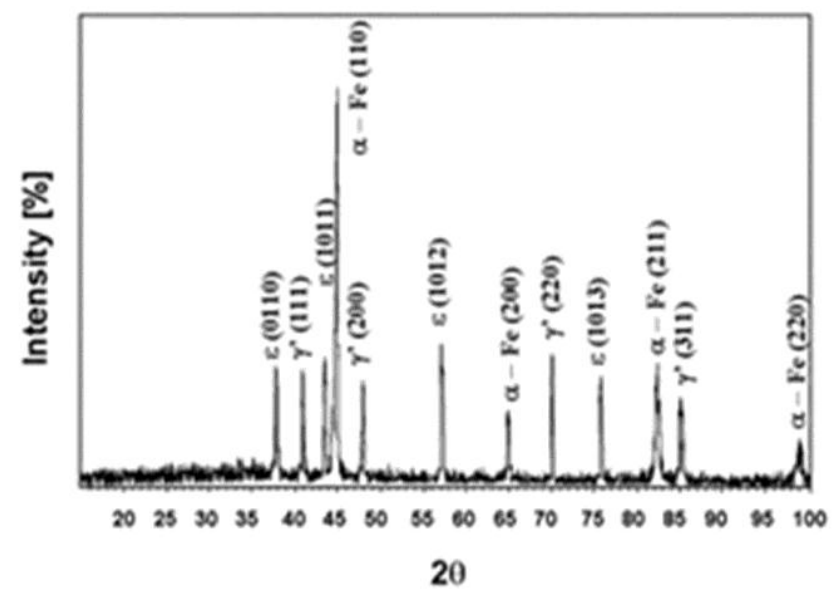

Figure 1. X-ray diffractogram of the nitriding sample nitrided during $5 \mathrm{~min}$.

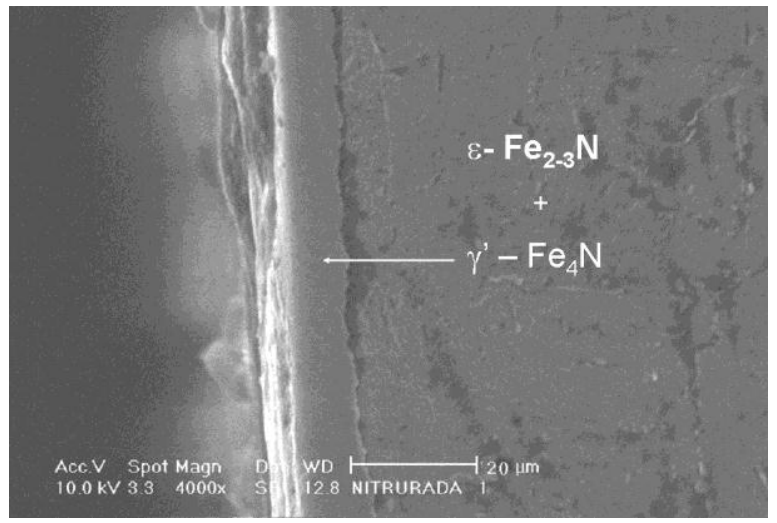

Figure 2. SEM image of the nitriding sample treated during $15 \mathrm{~min}$.

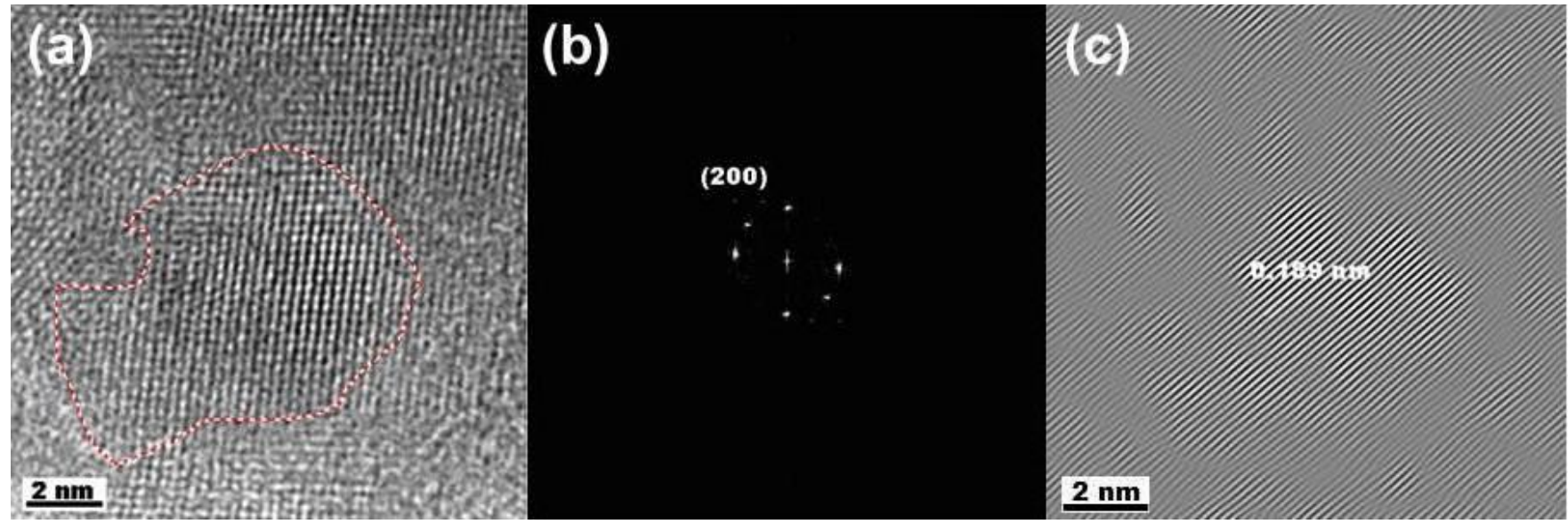

Figure 3. HRTEM image formed during 25 min of treatment: (a) Small precipitate of $\gamma^{\prime}-\mathrm{Fe}_{4} \mathrm{~N}$ nitride, (b) Fast Fourier Transform (FFT) image in the (200) plane and (c) Inverse of the Fast Fourier Transform (IFFT) image showing a interatomic distance of $0.189 \mathrm{~nm}$. 